\title{
Letramento e alfabetização nas práticas de ensino de uma docente participante do PNAIC - Educação Infantil
}

\author{
Literacy and initial reading instruction in the teaching practices of a teacher participating in \\ PNAIC - Early Childhood Education
}

\section{Littéracie et apprentissage initial de l'écrit dans les pratiques d'une enseignante participant au PNAIC-école maternelle}

\author{
Maria da Conceição Lira da Silva ${ }^{1}$ \\ Secretaria de Educação de Jaboatão dos Guararapes - PE \\ Alexsandro da Silva ${ }^{2}$ \\ Universidade Federal de Pernambuco
}

\begin{abstract}
Resumo: Este artigo analisa práticas de ensino de leitura e escrita desenvolvidas por uma docente de Educação Infantil que participou da formação do Pacto Nacional pela Alfabetização na Idade Certa (PNAIC). A pesquisa, de abordagem qualitativa, teve como campo um Centro Municipal de Educação Infantil. Os procedimentos metodológicos consistiram em observações, entrevistas e análise exploratória do acervo contemplado no curso. O tratamento dos dados, que se apoiou na análise temática de conteúdo, revelou que a docente contemplava as duas facetas da língua escrita - a alfabetização e o letramento. Percebe-se a mobilização de alguns elementos da formação do PNAIC, como o investimento na leitura literária e na análise fonológica.
\end{abstract}

Palavras-Chave: Formação continuada. Educação Infantil. Letrar e alfabetizar. Práticas de ensino.

Abstract: This article sought to analyze reading and writing teaching practices developed by an Early Childhood Education teacher who participated in the continuing education course of the National Pact for Initial Reading Instruction at the Right Age (PNAIC). The research adopted a qualitative approach, and had as its empirical field a Center for Early Childhood Education. The methodological procedures consisted in observations, interviews and exploratory analysis of the collection covered in the course. The data analysis, based on thematic content analysis, revealed that the teacher contemplated the two facets of the written language -literacy and initial reading instruction. We noticed the use of some elements of the PNAIC formation, such as the investment in reading literacy and the phonological analysis of words.

Keywords: Continuing Education. Early Childhood Education. Literacy and Initial reading instruction. Teaching practices.

\footnotetext{
1 Mestre em Educação pela Universidade Federal de Pernambuco. Coordenadora Pedagógica da Secretaria Municipal do Jaboatão dos Guararapes-PE. E-mail: cecalirases@gmail.com. Lattes: http://lattes.cnpq.br/4038094681262568. ORCID: https://orcid.org/o000-0003-3891-0483.

${ }_{2}^{2}$ Doutor em Educação pela Universidade Federal de Pernambuco. Professor Associado do Núcleo de Formação Docente do Centro Acadêmico do Agreste dessa mesma universidade, onde também atua no Programa de PósGraduação em Educação Contemporânea e no Programa de Pós-Graduação em Educação. E-mail: alexsandro.silva2@ufpe.br.Lattes: http://lattes.cnpq.br/2626338170888514. ORCID: https://orcid.org/oooo0002-1943-8227.
} 
Résumé: Cet article a cherché à analyser les pratiques d'enseignement de la lecture et de l'écriture développées par une professeure de l'école maternelle qui a participé à la formation du Pacte national pour l'apprentissage de la lecture et de l'écriture au bon âge (PNAIC). L'étude a adopté une approche qualitative, ayant une école maternelle comme lieu de recherche. Les procédures méthodologiques ont consisté à des observations, à des entretiens et à des analyses exploratoires du matériel utilisé dans le cours. Le traitement des données, basé sur une analyse thématique de contenu, a révélé que la professeure envisageait les deux facettes de la langue écrite - l'apprentissage initial de l'écrit et la littératie. Nous percevons la mobilisation de certains éléments de la formation du PNAIC, comme l'investissement dans la lecture littéraire et dans la conscience phonologique.

Mots clés: Formation continue. École maternelle. Littéracie et apprentissage initial de l'écrit. Pratiques d'enseignement.

Recebido em: 04 de maio de 2021 Aceito em: 17 de junho de 2021

\section{Introdução}

A formação continuada de professores é um direito assegurado na Lei de Diretrizes e Bases da Educação Nacional (LDB) n. ${ }^{\circ}$ 9.394/96 (BRASIL, [2019]). O Plano Nacional de Educação (PNE) garante, na meta 16, que a formação continuada dos profissionais de educação básica ocorrerá em sua área de atuação, considerando as necessidades, as demandas e as contextualizações dos sistemas de ensino (BRASIL, 2015). No entanto, a realidade ainda está distante do que apontam os documentos. O desafio torna-se maior quando nos reportamos à formação dos docentes que atuam na Educação Infantil, pois, por muito tempo, encontrávamos, nas escolas brasileiras, professores trabalhando nessa etapa de ensino sem possuir nem mesmo o nível médio. Diante da precariedade formativa desses docentes e da busca de cumprir a exigência da LDB n. ${ }^{\circ}$ 9.394/96, o Ministério da Educação lançou o Programa de Formação Inicial para Professores em Exercício na Educação Infantil (Proinfantil), que tinha como principal objetivo formar professores em nível médio.

Entre os programas de formação continuada de professores, destacamos, neste artigo, o Pacto Nacional pela Alfabetização na Idade Certa (PNAIC), que constituiu uma iniciativa da política pública nacional de incentivo à alfabetização, buscando "atender à Meta 5 do Plano Nacional da Educação (PNE), que estabelece a obrigatoriedade de alfabetizar todas as crianças, no máximo, até o final do $3^{\circ}$ (terceiro) ano do ensino fundamental.” (BRASIL, 2017, p. 3). Em 2017, a Educação Infantil foi inserida no Programa, sendo a primeira vez, no país, que a Educação Infantil passou a ser contemplada por um programa nacional de formação continuada envolvendo coordenadores 
Revista Educação e Políticas em Debate - v. 10, n. 2, p. 595-611, mai./ago. 2021 - ISSN 2238-8346

pedagógicos e professores desse nível de ensino. O curso ofertado teve por temática “Leitura e Escrita na Educação Infantil”, e o material disponibilizado pelo Ministério da Educação (MEC), em formato digital, para ser usado nesse curso foi o acervo de mesmo nome (Leitura e Escrita na Educação Infantil), produto de um contrato firmado entre a Diretoria de Currículos e Educação Integral (Dicei), a Secretaria de Educação Básica (SEB), o MEC e a Universidade Federal de Minas Gerais (UFMG), entre os anos de 2013 e 2015.

Nesse contexto, emergiu nosso objeto de pesquisa, o qual foi gestado a partir de diversas inquietações, que não constituem, necessariamente, questões de pesquisa. Listamo-las a seguir: como ocorre o trabalho docente com a leitura e a escrita na Educação Infantil? Como o PNAIC pode contribuir com as práticas dos docentes de Educação Infantil na perspectiva da alfabetização e do letramento? Como os professores participantes desse programa formativo materializam suas práticas docentes com a leitura e a escrita?

A pesquisa apresentada neste artigo, que assume uma abordagem qualitativa, tem como objetivo geral analisar práticas de ensino de leitura e escrita desenvolvidas por uma professora de Educação Infantil que participou da formação continuada ofertada no âmbito do PNAIC Educação Infantil (doravante PNAIC-EI). O campo de pesquisa eleito foi um Centro Municipal de Educação Infantil (Cemei) da rede de ensino de Jaboatão dos Guararapes, Pernambuco (PE), e a participante do estudo foi selecionada por meio de alguns critérios: ser professora efetiva da referida rede de ensino e ter participado de todos os encontros formativos do PNAIC-EI.

Neste artigo, analisamos elementos do curso do PNAIC-EI mobilizados por uma professora em suas práticas de ensino de leitura e escrita. Para isso, apresentaremos a estrutura do curso e o acervo nele trabalhado, assim como as referidas práticas desenvolvidas em sala de aula pela docente, a fim de estabelecer relações entre tais práticas e a formação continuada do PNAIC-EI. Nessa direção, recorremos, como instrumentos de produção dos dados, à aplicação de questionário ${ }^{3}$, à análise exploratória dos materiais usados no curso de formação, à observação participante e a entrevistas semiestruturadas, realizadas durante as observações e depois delas. Os dados gerados a partir desses procedimentos foram tratados por meio da análise de conteúdo (BARDIN, 2011).

O artigo está organizado em quatro partes. Logo após esta introdução, que constitui a primeira parte, abordamos a articulação entre letramento e alfabetização na Educação Infantil, tendo como princípios as interações e as brincadeiras. Na sequência,

\footnotetext{
${ }^{3} \mathrm{O}$ questionário foi utilizado para nos aproximarmos do campo de pesquisa e definirmos a participante da pesquisa. Esse instrumento foi composto por questões fechadas e abertas, respondidas individualmente na formação do PNAIC-EI.
} 
Revista Educação e Políticas em Debate - v. 10, n. 2, p. 595-611, mai./ago. 2021 - ISSN 2238-8346

discutimos sobre a formação continuada de professores e apresentamos o PNAIC-EI. Na terceira parte, expomos e discutimos os resultados da investigação relativa à análise das práticas de ensino de leitura e escrita da docente participante do estudo. Na quarta e última parte, expomos as considerações finais do artigo.

\section{Letrar e alfabetizar na Educação Infantil}

Considerando que as crianças estão inseridas em diferentes contextos sociais, nos quais são oferecidas distintas oportunidades de participação no universo da cultura escrita, iniciamos nossas reflexões sobre o tema a partir de uma discussão sociológica sobre capital cultural. A partir dessa premissa, autores como Bourdieu (2007) e Lahire (2012) evidenciam como a estrutura social possui uma desigual distribuição de poderes exercidos pelos capitais econômico, cultural, social e simbólico. Segundo tais autores, a transmissão do capital cultural ocorre, desde o nascimento, de forma dissimulada por meio da família e de outras instâncias. Nessa perspectiva, a origem social familiar contribui na trajetória escolar do indivíduo, pois crianças inseridas em ambientes mais letrados têm acesso a uma infinidade de bens culturais e chegam ao espaço escolar com uma bagagem cultural considerável.

Diante das desigualdades da sociedade brasileira, questionamos: as crianças da escola pública têm as mesmas oportunidades de acesso aos bens culturais relacionados à leitura e à escrita que as crianças da escola privada? A polêmica em torno dessa questão se torna maior quando se trata da discussão sobre ensinar ou não a língua escrita na Educação Infantil nas instituições públicas de ensino. A esse respeito, reportamo-nos a Kramer (2008, p. 66), que indaga: "Por que se começou a questionar o trabalho com a leitura e a escrita exatamente quando a população, antes excluída da Educação Infantil, começou a frequentá-la?” Essa é uma questão que merece ser pensada, pois as crianças da classe popular devem ter os mesmos direitos que as de classe média e alta, que, aos 5 anos de idade, já têm uma convivência intensa com o mundo da leitura e da escrita. Nessa direção, Morais (2012, p. 116) afirma que,

[...] para enfrentar o "apartheid educacional” do nosso país, a escola pública precisa iniciar, no final da educação infantil, um ensino que permita às crianças não só conviver e desfrutar, diariamente, de práticas de leitura e produção de textos escritos, mas também refletir sobre as palavras, brincando, curiosamente, com sua dimensão sonora e gráfica. 
Revista Educação e Políticas em Debate - v. 10, n. 2, p. 595-611, mai./ago. 2021 - ISSN 2238-8346

É dessa forma que concebemos o trabalho com a língua escrita na Educação Infantil, defendendo a integração entre letramento e alfabetização, ou seja, possibilitando o aprendizado do sistema de escrita alfabético, bem como o desenvolvimento de habilidades de uso desse sistema em práticas sociais. Consideramos a Educação Infantil como um espaço no qual devem ser oportunizadas aprendizagens de diferentes saberes, entre eles os da leitura e da escrita, não se devendo negar o direito das crianças de usufruírem da escrita e de se apropriarem desse bem cultural, ao mesmo tempo em que vivem plenamente sua infância.

Brandão e Leal (2010) apontam três caminhos distintos quando se trata do trabalho com a leitura e a escrita na Educação Infantil. Citamo-los na sequência: o da "obrigação da alfabetização", o do "letramento sem letras" e o "ler e escrever com significado na educação infantil”.

Na primeira concepção, a da "obrigação da alfabetização", o ensino se limita à cópia de vogais e famílias silábicas, com ênfase em habilidades de percepção e coordenação motora. Assim, nessa visão, a escrita é vista como código, e a aprendizagem limita-se à repetição e à memorização. Nessa perspectiva, como observa Morais (2012), as atividades têm como pressuposto uma concepção empirista/associacionista, de acordo com a qual as crianças aprendem passivamente recebendo informações transmitidas pelo adulto.

Já o segundo caminho, denominado de "letramento sem letras", parte da premissa de que na Educação Infantil não se deve ensinar a língua escrita, pois esse seria um conteúdo escolar que caberia ao Ensino Fundamental; assim, não haveria espaço na Educação Infantil para o ensino de letras. Vemos, nessa concepção, uma visão preconceituosa, na qual o ensino da língua escrita é concebido como algo negativo e pernicioso, que não deveria fazer parte do universo das crianças menores de 6 anos.

Esses dois caminhos são extremistas: ou se propõe um trabalho com a escrita de forma mecânica e repetitiva, ou se nega a presença dela. Brandão e Leal (2010) apresentam como alternativa um terceiro caminho, o "ler e escrever com significado na educação infantil", inspirado na concepção de Ferreiro e Teberosky (1999). Nessa visão, concebe-se que as crianças pensam sobre a escrita antes de serem alfabetizadas formalmente, construindo hipóteses. Concordamos com a consideração das autoras de que o terceiro caminho é o mais adequado, pois ele aponta para a

[...]a possibilidade de ensinar a escrita na Educação Infantil de forma sistemática, incluindo aspectos relativos à apropriação do sistema alfabético de escrita, sem desconsiderar os objetivos e as atividades do letramento, bem como outras necessidades relativas ao desenvolvimento e vivências da infância. (BRANDÃO; LEAL, 2010, p. 21). 
Assim, cabe ao professor propor desafios que permitam às crianças ampliar seus conhecimentos sobre a notação alfabética, pois o simples contato com tex tos por imersão não é suficiente para que os aprendizes se apropriem de alguns princípios do sistema alfabético. Dessa forma, com relação à faceta linguística da alfabetização (SOARES, 2017), deve haver um investimento em atividades que contribuam para o processo de apropriação da escrita alfabética e envolvam a dimensão lúdica. Brincando, as crianças comparam palavras quanto ao tamanho, descobrem rimas nas parlendas, brincam com vocábulos que tenham o mesmo som inicial e, assim, superam o realismo nominal ${ }^{4}$ e vão refletindo e se apropriando do sistema de escrita, desde que tenham oportunidades para fazê-lo.

Na seção a seguir, discutiremos sobre a formação continuada de professores. Enfocaremos, mais especificamente, a experiência formativa desenvolvida no âmbito do PNAIC-EI.

\section{Formação continuada de professores e a experiência formativa do PNAIC-EI}

A formação continuada dos professores é um tema muito discutido nos espaços educacionais. O intuito desses debates é o fortalecimento das práticas educativas por meio de investimentos nessa formação. No Brasil, por muito tempo, para ser professor de Educação Infantil, não era necessário formação, sendo um único requisito gostar de crianças. Nesse período, o foco da Educação Infantil estava centrado apenas no cuidar. Atualmente, os professores dessa etapa de ensino são vistos como profissionais responsáveis pelo binômio cuidar-educar e, portanto, necessitam de formação tanto inicial quanto continuada.

De acordo com Gatti et al. (2019), no cenário brasileiro, a partir da década de 1990, buscou-se superar o racionalismo técnico, tendo em vista que, nesse modelo de formação, o especialista ministrava a formação, e o professor apenas executava. Desse modo, havia

[...] uma cisão entre pesquisadores/especialistas, em relação aos
consumidores/executores. No primeiro caso, produzem conhecimento e
elaboram propostas, planos, programas e, no segundo, executam-se os
conhecimentos e ações produzidas e planejadas pelos
pesquisadores/especialistas. (GATTI et al., 2019, p. 181)

Na tentativa de superar esse modelo centralizado na técnica, passou-se a reconhecer o papel dos docentes e o espaço em que eles atuam, valorizando os saberes dos professores e promovendo reflexões que articulam teoria e prática. Outro aspecto relevante nessa direção

\footnotetext{
${ }^{4}$ É um modo de raciocínio que considera as palavras como portadoras das características (tamanho, aparência etc.) dos seres ou objetos representados.
} 
Revista Educação e Políticas em Debate - v. 10, n. 2, p. 595-611, mai./ago. 2021 - ISSN 2238-8346

diz respeito à aproximação entre as instituições de formação e a escola. Conforme Tardif(2011, p. 297), atualmente, observa-se uma tendência de valorização dos saberes da prática, na qual se busca "[ [...] reconhecer que os práticos do ensino possuem um saber original, oriundo do próprio exercício da profissão, que chamamos, conforme o caso, de 'saber experiencial', 'saber prático', ‘saber da ação’, ‘saber pedagógico’, ‘saber da ação pedagógica’, etc. [...]”.

Nessa perspectiva, torna-se necessário romper com o modelo de formação docente fundado na racionalidade técnica, buscando desenvolver uma cultura mais colaborativa, em que os docentes participem ativamente do processo formativo. Diante disso, a formação continuada enfrenta o desafio de contribuir mais efetivamente para as práticas desenvolvidas no interior da sala de aula.

Assim, o formador torna-se mediador do processo formativo, e os saberes dos professores, suas narrativas e suas práticas são legitimados e valorizados. Assume-se que, por meio da tematização das ações docentes, possibilita-se o olhar para o fazer do professor. Nessa visão, os docentes podem ser auxiliados a explicitar o que eles sabem fazer de maneira implícita, estabelecendo relações entre os saberes científicos e o fazer diário, o que pode contribuir para que (re)construam seus conhecimentos e suas práticas.

A formação continuada proposta no âmbito do PNAIC visou, desde sua implantação, em 2012, a romper com um modelo formativo atrelado aos velhos paradigmas, em que se observava o distanciamento das práticas. Em vez disso, propôs-se uma articulação entre os saberes teóricos e os práticos, valorizando os conhecimentos dos docentes. O caderno do PNAIC intitulado Formação de professores apresenta seis princípios a serem contemplados durante a formação: a prática da reflexividade; a mobilização dos saberes docentes; a constituição da identidade profissional; a socialização; o engajamento; e a colaboração. A mobilização dos saberes docentes é apresentada como um dos pontos centrais da formação continuada.

No contex to de Pernambuco, a formação do PNAIC-EI, que ocorreu entre 2017 e 2018, teve como instituição responsável o Centro de Estudos em Educação e Linguagem (Ceel) da Universidade Federal de Pernambuco (UFPE), em parceria com o MEC, a União Nacional dos Dirigentes Municipais de Educação (Undime) e as Secretarias de Educação de Pernambuco. O PNAIC-EI teve a adesão de 183 municípios pernambucanos e contou com um total de 335 cursistas, denominados formadores locais, que atuaram com 1.340 coordenadores pedagógicos e 6.252 professores de Educação Infantil, responsáveis por turmas de crianças de 4 e 5 anos.

Para a realização do curso, o MEC disponibilizou, em formato digital, o material Leitura e escrita na Educação Infantil, o qual é composto por um caderno introdutório de 
Revista Educação e Políticas em Debate - v. 10, n. 2, p. 595-611, mai./ago. 2021 - ISSN 2238-8346 apresentação e por mais oito cadernos que abordam, respectivamente, as seguintes temáticas: 1) Ser docente na Educação Infantil: entre o ensinar e o aprender; 2) Ser criança na Educação Infantil: infância e linguagem; 3) Linguagem oral e linguagem escrita na Educação Infantil: práticas e interações; 4) Bebês como leitores e autores; 5) Crianças como leitoras e autoras; 6) Currículo e linguagem na Educação Infantil; 7) Livros infantis: acervos, espaços e mediações; 8) Diálogo com as famílias: a leitura dentro e fora da escola.

O PNAIC-EI em Pernambuco foi organizado em 3 módulos, cada um com 24 horas presenciais, nos meses de dezembro de 2017, março e abril de 2018. A carga horária total do curso com os formadores locais foi de 104 horas. Como não foi possível abordar os oito cadernos em tão pouco tempo de formação presencial, tornou-se necessário selecionar alguns deles. Os formadores locais receberam impressos os cadernos 3, 5, 6 e 7 e cópias do artigo “Alfabetização e letramento na Educação Infantil”, de Magda Soares (2009), e de um capítulo do livro Ler e escrever na Educação Infantil: discutindo práticas pedagógicas (MORAIS; SILVA, 2010). Foram também inseridos vídeos e oficinas com jogos do Projeto Trilhas e do CEEL.

Os materiais formativos adicionados aos cadernos da coleção Leitura e escrita na Educação Infantil contemplavam a dimensão da apropriação do sistema de notação alfabética, abordada apenas muito tangencialmente nos volumes citados. Assim, em Pernambuco, buscouse contemplar as duas facetas da aprendizagem da língua escrita, assumindo, durante toda a formação, a perspectiva do letrar e do alfabetizar, considerando que, desde a Educação Infantil, já é possível abordar aspectos da alfabetização, o que não significa dizer que deve ser feito o ensino exaustivo de correspondências letra-som. Por outro lado, esse curso foi criticado em algumas instâncias locais com a alegação de que, na Educação Infantil, não se deveria trabalhar com os aspectos da faceta linguística da aprendizagem língua escrita, o que reflete os dissensos sobre o tema no campo acadêmico e no pedagógico.

Na rede municipal de ensino de Jaboatão dos Guararapes, onde realizamos a pesquisa, a formação do PNAIC-EI envolveu 12 formadoras locais e uma coordenadora geral, que atuaram com 231 professores. A partir de 2017, o MEC não ofereceu ajuda de custo aos professores, e alguns encontros formativos ocorreram aos sábados, fora da carga horária semanal de trabalho dos docentes. Assim, a formação ocorreu por adesão.

Após a análise das pautas formativas e dos relatórios das formadoras locais do município, percebemos que, no curso, foram usadas diferentes estratégias didáticas, como: leitura deleite, tarefas a serem realizadas em casa e na escola, estudo dirigido de textos, planejamento de atividades a serem feitas em sala de aula, socialização de memórias, vídeo em 
Revista Educação e Políticas em Debate - v. 10, n. 2, p. 595-611, mai./ago. 2021 - ISSN 2238-8346

debate, análises de situações de sala de aula filmadas ou registradas por escrito, análise de atividades das crianças e de recursos didáticos, exposição dialogada, elaboração de instrumentos de avaliação e discussão de seus resultados, além de avaliação da formação. Evidenciamos também, por meio dessa análise, que as duas facetas da aprendizagem da língua escrita, isto é, o letramento e a alfabetização, foram, de fato, contempladas na formação $P N A I C-E I$ da rede de ensino em tela.

\section{Letramento e alfabetização nas práticas de ensino de uma professora participante do curso de formação continuada do PNAIC-EI}

Nesta seção, analisaremos as práticas de ensino de leitura e escrita de uma professora participante do curso de formação continuada do PNAIC-EI. Para tanto, realizamos a triangulação dos dados gerados por meio das observações, das entrevistas e da análise das pautas formativas, dialogando com o referencial teórico adotado e com o material usado no curso. Os dados foram organizados em categorias temáticas, de acordo com Bardin (2011).

Conforme já dito na introdução, recorremos, para a produção dos dados principais da pesquisa, à observação participante e a entrevistas semiestruturadas, realizadas durante as observações e ao término destas. Após a seleção da docente que integrou o estudo, realizamos 10 dias de observação de aulas, que foram gravadas e transcritas na íntegra, além de termos feito registros por meio de fotos e filmagens. Recorremos também ao diário de campo para anotar nossas observações, pois ele constitui “o principal instrumento de trabalho de observação." (MINAYO, 2013, p. 71).

A professora participante do estudo atuava em um Cemei, localizado em uma comunidade carente, com um excelente espaço físico, atendendo às especificidades da Educação Infantil. Do ponto de vista da formação, a docente concluiu o curso de Pedagogia em 2009, além de ter realizado um curso de especialização em Docência na Educação Infantil, na Universidade Federal de Pernambuco, em 2016. Participou de todos os encontros do PNAIC-EI. Com relação à experiência profissional, tinha 10 anos de atuação em turmas de Educação Infantil.

A turma observada foi a do Infantil 5, que funcionava no turno da manhã, tendo 20 matriculados. Nessa turma, a acolhida das crianças era realizada com músicas infantis. As atividades permanentes conduzidas pela docente eram: roda de conversa; música de "bom dia”; marcação do calendário; contagem das meninas e dos meninos presentes; e leitura literária. As crianças tinham recreio na área externa; durante esse momento, a docente observava-os. Na volta do parque, as crianças lavavam as mãos e merendavam. Depois da merenda, geralmente conversavam um pouco e realizavam duas atividades 
Revista Educação e Políticas em Debate - v. 10, n. 2, p. 595-611, mai./ago. 2021 - ISSN 2238-8346

envolvendo diferentes linguagens. Durante as observações, vimos atividades envolvendo leitura e escrita na perspectiva do letrar e do alfabetizar, atividade de arte, brincadeira no terraço, circuito de brincadeira, ensaio para apresentação, construção de gráfico e exibição de vídeos sobre a temática deficiência.

\section{Práticas de leitura literária e mediação docente}

A literatura infantil esteve presente nas práticas da docente. As crianças interagiam com um acervo diverso, tendo ocorrido um investimento maior na leitura de tex tos literários, como lendas, contos, parlendas e trava-línguas.

A docente recorria a diferentes ambientes de leitura: cantinho na sala de aula, instalações na biblioteca e a biblioteca como um todo. Essa forma de organização é coerente com as três modalidades de espaços de leitura propostas por Perrotti, Pieruccini e Carnelosso (2016, p. 114) para a Educação Infantil, conforme indicado em um dos cadernos do curso de formação:

1. "Canto de Leitura" - ambiente localizado e implantado, em geral, nas salas das crianças, mas que pode estar em outros locais, com pátios, refeitórios, etc., simultaneamente ou não;

2. "Sala de Leitura" - ambiente especialmente preparado para uso de diferentes turmas e práticas, ligadas à apropriação da cultura escrita;

3. "Instalação de Leitura" - ambientes demarcados, quase sempre itinerantes e temporários. Podem estar num pátio, sob uma árvore ou mesmo numa sala de referência ou de leitura.

A forma de organização de cada espaço proposto nas práticas da docente dialogava com a ação pedagógica desenvolvida. Os livros selecionados para o espaço de leitura na sala eram adequados à faixa etária. Além disso, o acervo exposto estava sempre organizado na altura das crianças, o que chamava a atenção delas e as convidava para a leitura.

Quando questionamos a docente sobre quais temas do curso de formação do PNAICEI mais contribuíram para suas práticas de ensino de leitura e escrita em sala de aula, a professora destacou "literatura", "leitura e escrita" e "currículo". Vejamos o que ela disse na entrevista final sobre o tema literatura:

[...] teve a de literatura, que sempre é importante para que a gente possa renovar a nossa prática. Você viu aqui. Eu acho que [...] eu faço um trabalho buscando as orientações do PNAIC e das teorias, né, das pesquisas, das contribuições dos outros professores, porque esses trabalhos são contribuições de aprendizagem pra nós como professoras. Então ali, na temática ou no tema de literatura, também foi importante, foi renovação. Eu achei muito interessante, porque é um trabalho que eu já faço, 
Revista Educação e Políticas em Debate - v. 10, n. 2, p. 595-611, mai./ago. 2021 - ISSN 2238-8346

mais da contação de história. Como eu estou dizendo, a gente vai se renovando, sempre vai buscando alguma coisa.

Nesse extrato, a docente ressalta que a temática literatura foi relevante, e sua fala é coerente com o relatório da formadora local, pois, por meio da leitura e da análise desse material, vimos que as professoras da turma avaliaram de forma positiva o encontro que tratou da temática. Elas destacaram, em suas avaliações, os seguintes pontos interessantes: ideias para realizar leitura em sala, cantinhos da leitura, sala de leitura, organização do ambiente de leitura pensando nas crianças, estratégias para utilização do cantinho de leitura, além dos livros abordados e apresentados no curso (Relatório de F5, 9 abr. 2018).

Presenciamos, durante a geração dos dados, cinco situações de leitura literária na sala de aula e quatro ocasiões de visita à biblioteca, uma ação que estava inserida na rotina da turma. Nesse espaço, a docente organizou diferentes vivências. $\mathrm{O}$ extrato a seguir ilustra como a organização do espaço favoreceu o momento da leitura na biblioteca:

P (Professora) - Observem as mesinhas com os livros e escolham um livro para apreciação. Depois, vocês irão contar as histórias.

P - Atenção, concentração, hoje aqui na biblioteca vocês vão escolher o próprio livro: as lendas do folclore que estão ali na mesinha.

$\mathrm{P}$ - Observem bem as imagens, depois vocês irão ler para os colegas.

P - Lara pegou qual? Lara, qual tu queres? Cadê Lara? Qual é?

$\mathrm{P}$ - Mostra para teus amigos.

C (Criança) - Bicho papão! (disse Lara).

$\mathrm{P}$ - Vai Miguel, escolhe o teu. Lara, vamos ter cuidado com o livro.

$\mathrm{C}$ - Tia, e eu? (questionou Gabriela).

P - Vá lá na mesinha escolher o seu. Cadê seu livro, Rafael?

(Diário de campo, 10 ago. 2018)

Visualizamos que a docente estimulava as crianças a escolherem os livros. Após o momento de apreciação livre das obras, a professora organizou um círculo e convidou as crianças para contarem suas histórias, por meio das imagens, para os colegas. Durante a apresentação, ela estimulava os meninos e as meninas a olharem os detalhes das imagens e a narrar suas histórias. Foi um momento prazeroso para as crianças, que apresentaram seu livro, mostrando a capa, narrando a partir das imagens e seguindo a sequência da obra, uns com mais autonomia, outros com a ajuda da docente. Os pequenos mostraram diversidade de vocabulário, recontaram histórias que haviam sido lidas pela professora e, em alguns trechos, criaram narrativas.

Ressaltamos que, nos dias em que a leitura literária aconteceu no ambiente da sala de aula, a professora mediava a roda de leitura realizando perguntas de ativação de conhecimentos prévios e de previsão (antes e durante a leitura). Nesses momentos, a ela tinha uma escuta atenta e interagia com as crianças. 


\section{Práticas de ensino envolvendo o sistema de escrita alfabética desenvolvidas pela docente}

Ao observarmos as práticas de ensino com relação aos princípios do Sistema de Escrita Alfabética (doravante SEA) na turma em questão, visualizamos atividades envolvendo exploração de letras, consciência fonológica, jogos e produção de lista de palavras. A exploração de letras esteve bastante presente nas práticas da docente. Soares (2017, p. 209), ao discutir sobre a faceta linguística da alfabetização, ressalta a importância do conhecimento das letras, partindo do pressuposto de que "as crianças têm contato com as letras desde cedo, no contexto familiar e social e também em práticas que, já na educação infantil, precedem o ensino formal da língua escrita.”

Durante o período de observação, presenciamos duas atividades com letras móveis envolvendo composição de palavras, três situações de construção de listas com destaque de letras iniciais e três dias com escrita dos nomes, com foco na nomeação de letras. Cabe esclarecer que o ensino de letras envolvendo as fichas dos nomes próprios foi um trabalho mais individualizado, com apenas três crianças que apresentavam dificuldades de escrita de seu próprio nome e usavam as fichas como apoio, tendo em vista que as demais crianças da turma já escreviam o primeiro e o segundo nomes com autonomia.

Nas práticas da docente, as letras foram exploradas a partir de contexto significativo, pois não visualizamos nenhuma atividade envolvendo a mera cópia de letras. Em vez disso, presenciamos a realização de um trabalho com letras a partir da escrita do nome, de palavras, de lista ou da composição de palavras com letras móveis. $\mathrm{O}$ extrato a seguir ilustra como a docente valorizava esse saber. Nesse dia, as crianças nomearam as letras a partir da construção coletiva de uma lista com nomes de animais. A turma foi dividida em quatro grupos com três crianças, e a docente entregou as letras móveis para elas formarem os nomes dos animais.

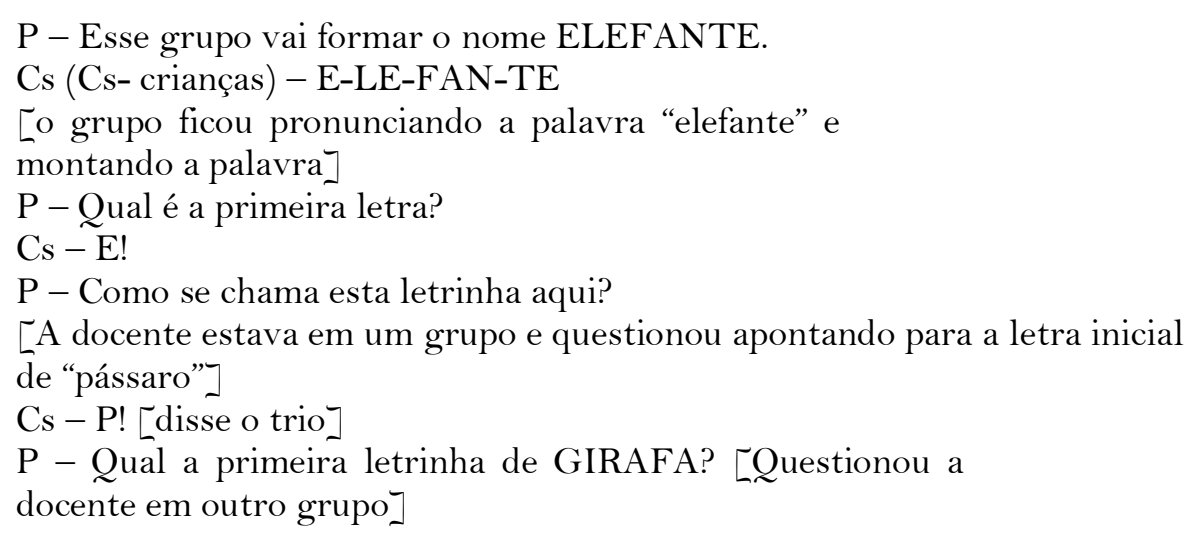


Revista Educação e Políticas em Debate - v. 10, n. 2, p. 595-611, mai./ago. 2021 - ISSN 2238-8346

P - Vamos procurar aqui! [a professora diz mostrando as letras móveis]

P - Para fazer GI, qual é a próxima letrinha?

(Diário de campo, 27 ago. 2017)

As crianças ficaram muito envolvidas na atividade, formando as palavras e silabando, enquanto a docente circulava nos grupos e levantava questionamentos. A professora permaneceu um tempo maior conversando com algumas crianças que, no momento da contagem de sílabas e letras na análise coletiva das palavras da lista, apresentaram maior dificuldade em diferenciar números de letras e sílabas. Um grupo teve maior autonomia e concluiu logo a atividade de composição de palavras. Diante disso, a docente propôs um novo desafio para essas crianças: escrever os nomes dos animais em um cartaz. Quando todos terminaram, a turma fez a leitura das palavras.

O investimento em atividades de reflexão fonológica nas práticas da docente nos chamou atenção, pois esteve presente em nove dos dez dias que observamos. As atividades de reflexão fonológica foram variadas: quatro englobaram identificação de som final (rima), uma foi de reconhecimento de aliteração, cinco envolveram contagem oral de sílabas e uma explorou a comparação do tamanho de palavras. De acordo com Soares (2017, p. 179), “a sensibilidade de crianças a rimas e aliterações tem sido considerada uma das dimensões da consciência fonológica que pode ter relações com a aprendizagem da leitura e da escrita."

No extrato abaixo, a docente realizou um trabalho a partir da leitura da parlenda "Upa, upa cavalinho", procurando desenvolver nas crianças habilidades que, segundo Morais (2012, p. 169), são possíveis de serem desenvolvidas por crianças no último ano da Educação Infantil: “segmentar palavras em suas sílabas e identificar palavras que rimam.” Inicialmente, a docente escreveu o texto no quadro em letra bastão e fez a leitura três vezes, apontando as palavras. Vejamos um trecho que ilustra como foi conduzida a atividade:

P- A-LA-ZÃO [a professora fez a leitura de forma silabada]

C3 - Parece Lara! [disse uma criança se referindo ao nome de uma colega de turma]

C3 - Tem o LA de Lara em ALAZÃO! [ [...]

$\mathrm{P}$ - Qual é a outra palavrinha que tem o mesmo som de mão?

$\mathrm{P}-\mathrm{Como}$ a gente descobre que tem a mesma rima?

C4 - ALAZÃ̃ e MÃO.

P - Jackson descobriu a palavra que tem a mesma terminação, que este pedacinho é igual. Muito bem!

$\mathrm{P}$ - Qual palavra termina igual cavalinho? CAVALINHO e LIGEIRINHO

C4-Aqui! [Apontou]

$\mathrm{P}$ - Muito bem!

$\mathrm{P}$ - Tem mais terminação igual? Tem mais? [...]

(Diário de campo, 17 ago. 2018) 
A docente realizou a leitura de maneira pausada, marcando as sílabas, forneceu pistas ajudando as crianças na localização de letras e palavras, pronunciou várias vezes as palavras que rimavam com o propósito de que percebessem os sons. Durante a análise das palavras, as meninas e os meninos fizeram associações com outros conhecimentos já construídos, como na situação em que uma das crianças relacionou a sílaba la de alazão ao nome da colega Lara. Percebemos que a professora pareceu atingir seu objetivo; ou seja, as crianças conseguiam realizar a atividade com identificação de rimas, mostrando que compreenderam a semelhança sonora entre as palavras.

Vimos, por meio da leitura do relatório da formadora local, que, na terceira formação do PNAIC-EI no município, foi estudado, conforme já dito, o texto "Consciência Fonológica na Educação Infantil: desenvolvimento de habilidades metalinguísticas e aprendizado da escrita alfabética” (MORAIS; SILVA, 2010). Nesse encontro de formação, também foram indicados jogos do CEEL (Bingo dos Sons Iniciais, Bingo da Letra Inicial, Dado Sonoro, Trinca Mágica, Caça-Rimas e Batalha de Palavras) e jogos do Projeto Trilhas (Descubra o Invasor, Batalha de Nomes e Rimas), alguns dos quais promovem a reflexão fonológica.

Diante do investimento que a docente fazia em atividades de reflexão fonológica, questionamos, na entrevista final, a professora sobre como elegeu esse aspecto como uma das prioridades de seu fazer cotidiano. Vejamos o que ela disse:

Eu brinco com as palavras, eu tenho essa preocupação, eu acredito neste trabalho. Tem pesquisas, e eu li a respeito dessa temática e quero colocar em prática. Eu li aquele livro Ler e escrever na Educação Infantil. Ele é um livro que é minha leitura deleite. Eu sempre, quando surge também alguma coisa, alguma dificuldade, até mesmo no meu planejamento, ou alguma dificuldade da criança, eu gosto daquele livro[...].

O depoimento da docente evidencia que o investimento que ela fazia nos aspectos fonológicos das palavras provém também de outro saber prévio e não apenas daquele obtido na formação continuada, pois a docente já havia lido aquela obra anteriormente. Como observa Tardif (2011, p. 54), o saber docente não é unitário, mas sim um "saber plural, saber formado de diversos saberes provenientes das instituições de formação, da formação profissional, dos currículos e da prática cotidiana, o saber docente é, portanto, essencialmente heterogêneo.”

Concluímos a análise destacando que a docente fabricava suas práticas contemplando o letramento e a alfabetização. As crianças pareciam felizes no espaço do Cemei e faziam diversas atividades envolvendo os demais campos de experiências, as quais não foram analisadas aqui, visto que não era nosso objeto de estudo. Todos os dias 
Revista Educação e Políticas em Debate - v. 10, n. 2, p. 595-611, mai./ago. 2021 - ISSN 2238-8346

elas brincavam no espaço externo. Além disso, presenciamos práticas explorando movimento, brincadeiras de circuitos, apresentações culturais abertas aos pais, trabalhos artísticos envolvendo artes visuais e dança.

\section{Considerações finais}

A análise das práticas da docente evidenciou a mobilização de elementos abordados durante a formação do PNAIC-EI. Ressaltamos, porém, que não pretendemos estabelecer uma relação direta e unilateral entre formação continuada e práticas de ensino, tendo em vista que os saberes e os fazeres dos docentes são oriundos de diversas fontes e não apenas da formação continuada.

As práticas observadas contemplavam aspectos do letramento e da alfabetização, explorando, principalmente, práticas de leitura de textos literários e atividades que envolviam o SEA. Com relação à leitura de textos literários, percebemos a leitura de histórias na sala de aula e na biblioteca. Visualizamos, também, algumas práticas contempladas no curso do PNAIC-EI, como o investimento em instalações de leitura, abordado durante o curso de formação. Com relação às práticas de ensino envolvendo o SEA, observamos que a docente investia na faceta linguística alfabetização, tendo como prioridades o conhecimento de letras e a consciência fonológica, por meio da exploração de rimas, parlendas e trava-línguas.

Os depoimentos da docente reforçaram que o curso foi significativo e potencializou algumas práticas já vivenciadas por ela, além de ter apontado esclarecimentos com relação a caminhos possíveis para o trabalho com a leitura e a escrita nessa etapa da escolarização. A docente declarou, na entrevista final, que o curso "foi muito importante", "foi uma renovação", "fortaleceu a prática”, "agregou à sua prática”. Relatou também que, após a formação, viu a necessidade de intensificar o trabalho com os jogos de reflexão fonológica, pois, apesar de a escola possuir esses materiais, ela recorria pouco a eles.

O modelo de PNAIC-EI em Pernambuco teve, como vimos, uma proposta formativa que contemplava os dois aspectos da aprendizagem inicial com a língua escrita na Educação Infantil: o letrar e o alfabetizar. Ressaltamos a necessidade de políticas formativas com mais tempo para essa discussão e para o aprofundamento dela, tendo em vista que os formadores locais tiveram 104 horas de formação, enquanto os professores tiveram acesso apenas a $20 \mathrm{~h}$. 
Revista Educação e Políticas em Debate - v. 10, n. 2, p. 595-611, mai./ago. 2021 - ISSN 2238-8346

\section{Referências}

BARDIN, Laurence. Análise de conteúdo. Tradução: Luis Antero Reto e Augusto Pinheiro. Portugal: Edições 70, 2011.

BOURDIEU, Pierre. A escola conservadora: as desigualdades frente à escola e à cultura. In: NOGUEIRA, Maria Alice; CATANI, Afrânio (org.) Escritos de educação. Petrópolis, RJ: Vozes, 2007. p. 39-64.

BRANDÃO, Ana Carolina Perrusi; LEAL, Telma Ferraz. Alfabetizar e letrar na Educação Infantil: o que isso significa? In: BRANDÃO, Ana Carolina Perrusi; ROSA, Ester Calland de Souza. Ler e Escrever na Educação Infantil: discutindo práticas pedagógicas. Belo Horizonte: Autêntica, 2010. p. 13-31.

BRASIL. Instituto Nacional de Estudos e Pesquisas Educacionais Anísio Teixeira. Plano Nacional de Educação PNE 2014-2024: Linha de Base. Brasília, DF: Inep, 2015.

BRASIL. Lei $n^{\circ}$ 9.394, de 20 de dezembro de 1996. Estabelece as diretrizes e bases da educação nacional. Brasília, DF: Presidência da República, [2019]. Disponível em:

http://www.planalto.gov.br/ccivil 03/leis/19394.htm. Acesso em: 08 ago. 2020.

BRASIL. Ministério da educação. Pacto Nacional pela Alfabetização na Idade Certa. Brasília, DF: MEC, 2017. Disponível em: http://pacto.mec.gov.br/documento-orientador. Acesso em: 11 mar. 2018.

BRASIL. Ministério da Educação. Proinfantil: Programa de Formação Inicial para Professores em Exercício na Educação Infantil: Sistema de Informação do Proinfantil Brasília, DF: MEC, [20--]. Disponível em: http://proinfantil.mec.gov.br/. Acesso em: 5 mar. 2012.

FERREIRO, Emília; TEBEROSKY, Ana. A psicogênese da língua escrita. São Paulo: Artmed, 1999.

GATTI, Bernardete; BARRETO, Elba Siqueira de Sá; ANDRÉ, Marli Eliza Dalmazo Afonso de André; ALMEIDA, Patrícia Cristina Albieri de. Professores do Brasil: novos cenários de formação. Brasília, DF: Unesco, 2019.

KRAMER, Sonia. Direitos da criança e projeto político pedagógico de educação infantil. In: BAZÍLIO, Luiz Cavalieri; KRAMER, Sonia (org.). Infância, educação e direitos humanos. 3. ed. São Paulo: Cortez, 2008. p. 51-81.

LAHIRE, Bernard. A transmissão cultural da ordem desigual das coisas. Pátio, Porto Alegre, ano XV, n. 60, p. 6-9, nov. 2011/jan. 2012.

MINAYO, Maria Cecília de Sousa. Pesquisa social: teoria, método e criatividade. 33. ed. Petrópolis, RJ: Vozes, 2013.

MORAIS, Artur Gomes de. Sistema de escrita alfabética. São Paulo: Melhoramentos, 2012. 
MORAIS; Artur Gomes de; SILVA, Alessandro da. Consciência fonológica na Educação Infantil: desenvolvimento de habilidades metalinguísticas e aprendizado da escrita alfabética. In: BRANDÃO, Ana Carolina Perrusi; ROSA, Ester Calland de Sousa (org.). Ler e escrever na Educação Infantil: discutindo práticas pedagógicas. Belo Horizonte: Autêntica, 2010. p. 73-91.

SOARES, Magda. Alfabetização: a questão dos métodos. 1. ed. 1. reimp. São Paulo: Contexto, 2017.

SOARES, Magda. Alfabetização e letramento na educação infantil. Pátio, Porto Alegre, ano VII, n. 20, jul./out. 2009.

PERROTTI, Edmir; PIERUCCINI, Ivete; CARNELOSSO, Rose Mara Gozzi. Os Espaços do Livro nas Instituições de Educação Infantil. In: BRASIL. Ministério da Educação. Secretaria de Educação Básica. Livros infantis: acervos, espaços e mediações. Brasília: SEB/MEC /, 2016. p. 113- 150. (Coleção Leitura e escrita na educação infantil, v. 7).

TARDIF, Maurice. Saberes docentes e formação profissional. 12. ed. Petrópolis, RJ: Vozes, 2011. 